\title{
The Protective Effect of Berberis aristata against Mitochondrial Dysfunction Induced due to Co-administration of Mitomycin C and Cisplatin
}

\author{
Kavita Kumari $\mathrm{K}^{1 *}$ and Setty $\mathrm{OH}^{2}$
}

${ }^{1}$ Jawaharlal Nehru Institute of Advanced Studies (JNIAS), 6th Floor, Buddha Bhawan, M. G. Road, Secunderabad - 500003, Andhra Pradesh, India ${ }^{2}$ Department of Biochemistry, School of Life Sciences, University of Hyderabad, Gachibowli, Hyderabad 500046, India

\begin{abstract}
Background: The combination of mitomycin $\mathrm{C}$ and cisplatin was proved to be beneficial in the treatment of lung cancer, breast cancer, anal carcinoma and human cervical cancer treatment. However, dose related toxicity happens to be one of the major concerns the treatment, leading to its discontinuation, although the patient's response is encouraging The aim of the present investigation was to study the protective effects of Berberis aristata (10 mg/kg body weight) on the mitochondrial dysfunction caused due to administration of mitomycin C (2 mg/kg body wt, i.p) and cisplatin (12 mg/ kg body wt, i.p).
\end{abstract}

Methods: We have investigated the effects and protective effects on oxidative phosphorylation, enzymes of the electron transport system, lipid peroxidation and phospholipid composition in liver and kidney mitochondria.

Results: Co-administration of mitomycin $\mathrm{C}$ and cisplatin resulted in significant decrease in active respiration (State 3 Respiration), Respiratory Control Ratio (RCR) and P/O ratio's using either succinate or glutamate plus malate as substrate. Altered enzyme activities of NADH dehydrogenase, succinate dehydrogenase, succinatecytochrome $c$ reductase, $\mathrm{NADH}$-cytochrome $c$ reductase, cytochrome $c$ oxidase was observed. The levels of lipid peroxides were significantly increased, accompanied with a significant decrease in phospholipid content. Prior administration of Berberis aristata protected against observed mitochondrial dysfunction.

Conclusions: Our results demonstrate that prior administration of Berberis aristata could reduce the damage to mitochondrial function, by scavenging free radicals and thereby, preventing uncoupling of oxidative phosphorylation, deactivation of enzymes of electron transport chain, generation of lipid peroxides, oxidation of phospholipids ultimately inhibiting the signaling wave propagation to the mitochondria death receptor (membrane bound cytochrome $c$ ), which generally leads to apoptosis.

Keywords: Berberis aristata; Mitochondria; Oxidative phosphorylation; RCR; P/O ratio; NADH; Succinate; Cytochrome $c$; Free radicals; Lipid peroxides

Abbreviations: ADP: Adenosine diphosphate; BSA: Bovine Serum Albumin; EDTA: Ethylene Diamine Tetraacetic Acid; FAD: Flavin Adenine Dinucleotide; MDA: Malonaldehyde Bis (Dimethyl Acetal); NADH: Nicotinamide Adenine Dinucleotide (Reduced); P/O: Phosphate to Oxygen Ratio; RCR: Respiratory Control Ratio; ETC: Electron Transport Chain; ROS: Reactive Oxygen Species

\section{Introduction}

Cisplatin (cis-diaminedichloroplatinum (II) CDDP), is a platinum-containing anticancer drug. It is one of the routinely used cytotoxic agent, used in the treatment of a variety of malignancies $[1,2]$. Despite its excellent anticancer activity, its clinical use is often limited by its undesirable side effects, such as severe nephrotoxicity and hepatotoxicity [1,3-5]. After a single dose of cisplatin, there is preferential sequestration of the drug in the kidney, liver, intestine, and testis with concentration in the kidney reaching 37 times higher, in comparison to plasma [6]. Although, DNA damage followed by apoptosis was indicated as a primary cytotoxic mechanism of cisplatin [7] it was observed that cisplatin induced cell death occurs at a concentration that does not inhibit synthesis of DNA [8,9], indicating alternative mechanism of action. Cisplatin is shown to interact with DNA and proteins and it is possible that the damage to cytoplasmic proteins is an early event in the process of cisplatin-induced apoptosis [10,11]. Involvement of cisplatin in stress response in both cancer cells [12] and normal kidney proximal tubule cells [13], indicates that cisplatin may initiate apoptosis from the cytoplasm [14]. Some of the adverse effects reported with overdose of cisplatin are kidney and liver failure, myelosuppression, neuropathy, ototoxicity and blindness [15]

Mitomycin C is a naturally occurring antibiotic originally isolated from the Gram-negative bacteria Streptomyces caespitosus. It is used as a chemotherapeutic agent for the treatment of bladder, colon, breast, gastrointestinal, lung, gynecologic, head and neck cancer $[16,17]$. Its ability to potentiate the response of cells, resistant to cisplatin as a single agent has been proved by earlier investigators [18-20]. The combination of mitomycin $\mathrm{C}$ and cisplatin was proved to be beneficial in lung cancer [21], breast cancer [22], anal carcinoma and human cervical cancer treatment [23]. Thus we have selected the combination of mitomycin $\mathrm{C}$ and cisplatin for the present investigation.

*Corresponding author: Dr. Kavita Kumari K, Current Affiliation: Jawaharla Nehru Institute of Advanced Studies (JNIAS), 6th Floor, Buddha Bhawan, MG Road, Secunderabad-500003, Andhra Pradesh, India, Tel: 040-27541551; E-mail: kavitakakarala@gmail.com

Received June 04, 2012; Accepted July 07, 2012; Published July 09, 2012

Citation: Kavita Kumari K, Setty OH (2012) The Protective Effect of Berberis aristata against Mitochondrial Dysfunction Induced due to Co-administration of Mitomycin C and Cisplatin. J Cancer Sci Ther 4: 199-206. doi:10.4172/19485956.1000142

Copyright: () 2012 Kavita Kumari K, et al. This is an open-access article distributed under the terms of the Creative Commons Attribution License, which permits unrestricted use, distribution, and reproduction in any medium, provided the original author and source are credited. 
Citation: Kavita Kumari K, Setty OH (2012) The Protective Effect of Berberis aristata against Mitochondrial Dysfunction Induced due to Coadministration of Mitomycin C and Cisplatin. J Cancer Sci Ther 4: 199-206. doi:10.4172/1948-5956.1000142

Mitochondria produce the majority of cellular ATP through oxidative phosphorylation and carry out several other crucial metabolic processes [24]. The oxidative phosphorylation is so far the major source of ATP in mammalian cells relying on aerobic energy metabolism. The electron transport chain (ETC) consists of: a) three major protein assemblies: mitochondrial respiratory complex I (NADH:ubiquinone oxidoreductase), complex III (ubiquinol:ferricytochrome $c$ oxidoreductase) and complex IV (cytochrome $c$ oxidase), which build up transmembrane electrochemical potential $(\psi)$ by coupling their electron transfer activities to $\mathrm{H}^{+}$translocation from the matrix (negative) to the outer (positive) side of the inner mitochondrial membrane, and b) two mobile carrier molecules, ubiquinone (Coenzyme Q) and cytochrome $c$. The electrochemical gradient is then utilized for ATP synthesis by complex V (ATP synthase). Succinate-Q oxidoreductase, which is part of the tricarboxylic acid cycle, is also assigned to the respiratory chain as complex II. All the respiratory chain complexes are made up of numerous polypeptides and contain a series of different protein-bound redox coenzymes, including flavins (FMN or FAD in complexes I and II), iron-sulfur clusters (in I, II, and III), and hemes (in II, III and IV) reviewed in [25]. Earlier studies from our lab had reported that mitochondrial dysfunction was caused by the administration of alcohol [26], thioacetamide [27], carbon tetrachloride [28] and cisplatin and cyclophosphamide [29].

Studies have indicated that a combination of an effective phytochemicals with chemotherapeutic agents would enhance drug efficacy, while reducing toxicity to normal tissues [30]. Berberis aristata (B.aristata) DC, known as 'Daru haldhi' in Ayurvedic system of medicine, is extensively used in various systems of indigenous medicine for treating a variety of ailments such as eye and ear diseases, rheumatism, jaundice, diabetes, stomach disorders, skin disease, malarial fever and as tonic etc. Phytochemical studies show that the plant contains alkaloids like berberine, aromoline, karachine, palmatine, oxyacanthine and oxyberberin reviewed in [31]. The species of $B$. aristata is known for its hepatoprotective activity against hepatic amoebiasis and is used in immunomodulation studies [32]. Posttreatment with three successive doses of the extract $(500 \mathrm{mg} / \mathrm{kg}, 6 \mathrm{~h})$ restricted the hepatic damage induced by acetaminophen ( $p$ less than 0.01 ) but $\mathrm{CCl}_{4}$-induced hepatotoxicity was not altered. The plant extract $(500 \mathrm{mg} / \mathrm{kg}$ ) caused significant prolongation in pentobarbital $(75 \mathrm{mg} /$ $\mathrm{kg}$ ) induced sleep as well as increased strychnine-induced lethality in mice suggestive of inhibitory effect on microsomal drug metabolizing enzymes (MDME).

Hepatoprotective action of the crude extract of $B$. aristata fruits partly through MDME inhibitory action has been indicated [33]. Thus the present study was undertaken to investigate the protective effect of $B$. aristata against mitochondrial dysfunction induced due to coadministration of mitomycin $\mathrm{C}$ and cisplatin.

\section{Materials and Methods}

\section{Animals}

Albino Wistar rats weighing $120 \pm 20 \mathrm{~g}$ were taken from the animal house facility of the University of Hyderabad and checked for proper growth for at least 8-10 days. They were fed with commercial pellet diet and tap water ad libitum. Alcoholic extract of B. aristata was obtained from local homeo stores. B. aristata dosage/time was standardized based on the results obtained after treating rats with different concentrations B. aristata and measuring the extent of protection offered by them. The standardized dose was also checked for its effect, to rule out toxicity of $B$. aristata when administered alone.

\section{Treatment of experimental animals}

The animals were divided into four groups of six animals each.

Group1: Rats received saline.

Group 2: Rats received a single dose of mitomycin C (2 mg/kg body weight, i.p.) and cisplatin (12 $\mathrm{mg} / \mathrm{kg}$ body weight, i.p). Rats were sacrificed $48 \mathrm{~h}$ after the administration of drugs.

Group 3: Alcoholic extract of B. aristata $(10 \mathrm{mg} / 100 \mathrm{~g}$ body weight, oral) was given for three days.

Group 4: Alcoholic extract of B. aristata $(10 \mathrm{mg} / 100 \mathrm{~g}$ body weight, oral) was given for three days and then followed by single dose of mitomycin C ( $2 \mathrm{mg} / \mathrm{kg}$ body weight, i.p) and cisplatin $(12 \mathrm{mg} / \mathrm{kg}$ body weight, i.p). Rats were sacrificed $48 \mathrm{~h}$ after the administration of drugs.

\section{Isolation of mitochondria}

A slightly modified method of Lawrence and Davies [34] was used for the preparation of mitochondria. Briefly, $10 \%$ liver homogenate was prepared using Potter Elevehjem homogenizer with a Teflon pestle in ice cold medium A (70 mM sucrose, $220 \mathrm{mM}$ mannitol, $2 \mathrm{mM}$ HEPES, $0.2 \mathrm{mM}$ EDTA and $0.36 \mathrm{mg} / \mathrm{ml}$ of BSA, pH 7.4) followed by differential centrifugation. For isolation of kidney mitochondria the kidney capsules were removed by gently squeezing it in between the thumb and fore finger. The kidney was cut and the medullary portion was discarded. Mitochondria were then prepared from the cortex portion following the same method as described for the liver. The final pellet containing mitochondria was suspended in medium B (70 mM sucrose, $220 \mathrm{mM}$ mannitol, $\mathrm{pH}$ 7.4). The protein content was determined using Biuret method with BSA as a standard [35]. Mitochondria were used immediately for the measurement of oxidative phosphorylation and then stored at $-80^{\circ} \mathrm{C}$ for biochemical assays. All procedures were carried out at $4^{\circ} \mathrm{C}$.

\section{Measurement of oxygen consumption}

Polarographic determination of oxidative phosphorylation was carried out according to Estabrook [36] with Gilson 5/6 oxygraph fitted with a Clark type of electrode. Respiration rates were measured at $25^{\circ} \mathrm{C}$ in a buffer (containing $50 \mathrm{mM}$ sucrose, $50 \mathrm{mM}$ Tris- $\mathrm{HCl}, 20 \mathrm{mM}$ potassium phosphate, $2 \mathrm{mM}$ EDTA, $7 \mathrm{mM} \mathrm{MgCl}_{2}$ chloride, $\mathrm{pH}$ 7.4) and 1-2 mg of freshly isolated mitochondrial protein using an oxygen electrode disc in an airtight chamber of $1 \mathrm{ml}$ volume. Malate $(4 \mathrm{mM})$ and glutamate $(2 \mathrm{mM})$ or succinate $(9 \mathrm{mM})$ was used as the substrates. Respiratory control ratio (RCR) was obtained from the ratio of ADP stimulated state- 3 respiration to ADP exhausted state- 4 respiration and $\mathrm{ADP} / \mathrm{O}=\mathrm{P} / \mathrm{O}$ ratio which was calculated according to Estabrook [36]. Respiration was initiated by the addition of $9 \mathrm{mM}$ sodium succinate or $2 \mathrm{mM}$ glutamate plus $4 \mathrm{mM}$ malate for succinate oxidase and $\mathrm{NADH}$ oxidase, respectively. State- 3 respiration was measured by the addition of 200 and $400 \mathrm{nM}$ of ADP for succinate oxidase and NADH oxidase, respectively.

NADH dehydrogenase: [NADH: (Acceptor) oxidoreductase, EC 1.6.5.3]: NADH dehydrogenase was measured using potassium ferricyanide as electrode acceptor [37]. The reaction system contained 250 $\mathrm{mM}$ sucrose, $30 \mathrm{mM}$ Tris- $\mathrm{Hcl}, 10 \mathrm{mM}$ Potassium phosphate, $5 \mathrm{mM}$ $\mathrm{MgCl}_{2}, 1 \mathrm{mM} \mathrm{KCN}, 1 \mathrm{mM}$ Pottasium ferriccynide, $\mathrm{pH} 7.4$ and $20 \mu \mathrm{g}$ of mitochondrial protein (frozen and thawn) in a reaction volume of $1 \mathrm{ml}$. 
Citation: Kavita Kumari K, Setty OH (2012) The Protective Effect of Berberis aristata against Mitochondrial Dysfunction Induced due to Coadministration of Mitomycin C and Cisplatin. J Cancer Sci Ther 4: 199-206. doi:10.4172/1948-5956.1000142

The reaction was initiated by the addition of NADH $(1.5 \mathrm{mM})$ and the rate of reduction of ferric cyanide was followed at $420 \mathrm{~nm}(\mathrm{E} \mathrm{mM}=1.0)$.

Succinate dehydrogenase: [Succinate: (Acceptor) oxide reductase, EC 1.3.5.1]: Succinate dehydrogenase was assayed using dichorophenol indophenol (DCPIP) as an electron donor [38]. The reaction system was same as that used NADH dehydrogenase assay except that potassium ferricyanide was substituted by $1 \mathrm{mM}$ phenazine methosulfate (PMS) and $70 \mu \mathrm{M}$ DCPIP. The rate of reduction of DCPIP was followed at $600 \mathrm{~nm} .10 \mu \mathrm{g}$ of mitochondrial protein was incubated with $10 \mu \mathrm{l}$ of $0.5 \mathrm{M}$ sodium succinate $(\mathrm{pH}=7.4)$ at room temperature for 10 min before assaying SDH activity $(\mathrm{E} \mathrm{mM}=16.9)$.

Succinate- cytochrome $c$ reductase: [Succinate: Ubiquinone Oxido reductase, EC 1.3.99.1]: The activity of Succinate-cytochrome $c$ reductase was determined by the modified method of Tisdale [39]. The reaction was carried out in a total volume of $1 \mathrm{ml}$ and consisted of buffer (10 mM Pottasium phosphate, $0.8 \mathrm{mM}$ EDTA, $0.25 \mathrm{M}$ Sucrose, pH 7.4) $5 \mathrm{mM}$ succinate, $1 \mathrm{mM} \mathrm{KCN}, 2 \mathrm{n}$ moles of rotenone and 130 nmoles of ferric cytochrome C. The reaction was initiated by adding 20 $\mathrm{mg}$ of mitochondrial protein. The increase in the absorbance at $550 \mathrm{~nm}$ was followed $(\mathrm{E} \mathrm{mM}=19.1)$.

NADH-cytochrome $c$ reductase: [NADH: Ubiquinone Oxidoreductase, EC 1.6.99.3]: NADH-cytochrome $c$ reductase was determined by the modified method of Hatefi and Reiske [40]. The reaction mixture consisted of (1.0 M potassium phosphate- $\mathrm{HCl}$ buffer). $1 \mathrm{M} \mathrm{NaN}_{3}$, $1 \mathrm{mM}$ EDTA, $1 \%$ deoxycholate, $\mathrm{pH} 8.0$ and $1 \%$ ferric cytochrome C. $20 \mu \mathrm{g}$ of mitochondrial suspension was taken and the reaction was initiated by the addition of $10 \mathrm{mM} \mathrm{NADH}$. After 15 second incubation at $30^{\circ} \mathrm{C}$, the reaction was followed for one minute by recording the increase in absorbance of cytochrome $c$ at $550 \mathrm{~nm}$. The activity of $\mathrm{NADH}$-cytochrome $\mathrm{c}$ was deduced from increasing rate of absorbance $(\mathrm{E} \mathrm{mM}=19.1)$

Cytochrome $c$ oxidase (EC 1.9.3.1): The enzyme was assayed by following the decrease in the absorbance of ferro cytochrome $\mathrm{C}$ at 550 $\mathrm{nm}$ [41]. The reaction was initiated by addition of $1 \mathrm{mg}$ protein (E $\mathrm{mM}=19.1)$.

Preparation of reduced cytochrome $c: 17 \mathrm{mg}$ of Cytochrome $c$ was dissolved in $20 \mathrm{ml}$ of $30 \mathrm{mM}$ Pottasium Phosphate buffer, pH 7.4. It was then reduced by addition of small amounts of sodium dithionate [42] excess sodium dithionate was removed by dialysis against $30 \mathrm{mM}$ phosphate buffer, $\mathrm{pH} 7.4$ for $10-20 \mathrm{hr}$ with three to four changes of buffer.

Assay of lipid peroxides by Thiobarbituric acid reaction: Lipid peroxide level was determined in liver and kidney homogenates and mitochondria [43]. A $10 \%$ homogenate was prepared in $1.15 \% \mathrm{KCl}$ using potter elevehjem homogenizer. Mitochondria were washed with $1.15 \% \mathrm{KCl}$ and suspended in the same medium. Protein estimation was done by Biuret method [35]. To $5 \mathrm{mg}$ protein, $0.2 \mathrm{ml}$ of $8.1 \%$ SDS, $1.5 \mathrm{ml}$ of $20 \%$ acetic acid (adjusted to $\mathrm{pH} 3.5$ with $\mathrm{NaOH}$ ) and $1.5 \mathrm{ml}$ of $0.67 \%(\mathrm{w} / \mathrm{v})$ aqueous solution of thiobarbituric acid were added. The total volume was made up to $4.0 \mathrm{ml}$ with distilled water and the tubes were heated in a water bath at $95^{\circ} \mathrm{C}$ for $60 \mathrm{~min}$ using marble as a condenser. A blank was also run simultaneously and tetramethoxy propane was used as an external standard. After cooling, $1 \mathrm{ml}$ of distilled water and $5 \mathrm{ml}$ of $\mathrm{n}$-butanol were added, vortexed and then centrifuged at $4000 \mathrm{rpm}$ for $10 \mathrm{~min}$ at room temp. The absorbance of organic layer was measured at $535 \mathrm{~nm}$. The level of lipid peroxides is expressed as $\mathrm{n}$ moles of MDA formed/100 mg protein.
Separation of mitochondrial phospholipids: Thin layer chromatography was used for the separation of phospholipids. Mitochondrial lipid was extracted by the procedure of Bligh and Dyer [44]. About 6-8 mg of mitochondrial was used. The phospholipids were separated using Chloroform: methanol: water (65:25:4). Inorganic phosphorus was estimated [45]. It is expressed as phospholipid phosphorus/gm tissue.

\section{Chemicals}

Cisplatin [cis-Diamminedichloroplatinum (II)] and Mitomycin $\mathrm{C}$ were purchased from local medical stores. ADP, NADH, bovine serum albumin (BSA), Hepes [N-(2-hydroxyethyl) piperazine-N-(2ethanesulfonicacid)], EDTA (ethylene diamine tetra acetic acid) and cytochrome $c$, were purchased from Sigma Chemical Co. (St. Louis, MO, USA). Sucrose and mannitol were purchased from MERK (Darmstadt, Germany). All the other chemicals were of research grade. Commercially reconstituted CDDP and mitomycin $c$ solution was used. Solutions/Buffers were prepared with double distilled water.

\section{Statistical analysis}

All the values are expressed as mean \pm S.D. Statistical significance was calculated using students $t$ test where $\mathrm{P}<0.05$ was considered to be significant.

\section{Results}

The present investigation was undertaken to understand the mechanism of toxicity of anticancer drugs mitomycin $\mathrm{C}$ and cisplatin. This study was mainly focused on their effects on enzymes of mitochondrial electron transport chain, membrane integrity as measured by RCR, $\mathrm{P} / \mathrm{O}$ ratios, level of lipid peroxides and changes in phospholipid composition.

The dose and time duration of mitomycin $\mathrm{C}$ and cisplatin was studied as a function of time and then treatment plan was finalized. A similar study was undertaken to finalize the dose and duration of treatment with B.aristata. Treatment schedule was followed as mentioned in the methods section. To avoid experimental errors more than six rats were included in each group. Results of all the parameters in this study are expressed relative to control, which was taken as 100 . The actual values for the control group are given in the corresponding figures.

\section{Effects on oxidative phosphorylation}

Externally added NADH cannot penetrate the tightly coupled mitochondria, hence, glutamate and malate were used to reduce the $\mathrm{NAD}^{+}$pool in the matrix, which was then oxidized by the respiratory chain. NADH oxidase gives information on the ability of transfer of electrons through all three sites of the electron transport chain. There was a significant decrease in State 3 respiration (28\%), Respiratory control ratio (RCR) (32\%) and $\mathrm{P} / \mathrm{O}$ ratios (28\%), when glutamate and malate were used as substrates (Figure 1). Similarly, State 3 (26\%), RCR (30\%) and $\mathrm{P} / \mathrm{O}$ ratios (33\%) were decreased, when succinate was used as substrate. These effects were observed in the liver mitochondria of group-2 (mitomycin $\mathrm{C}+$ cisplatin) rats, when they were compared with group-1 (control) rats (Figure 2). Whereas, in group-4 rats (B. aristata + mitomycin $C+$ cisplatin), prior administration of $B$. aristata, showed protection against observed decrease in state 3 respiration (The actively respiring state is referred to as state 3 respiration, while the slower rate after all the ADP has been phosphorylated to form ATP is referred to as state 4) RCR (Respiratory control ratio) and $\mathrm{P} / \mathrm{O}$ ratios (The $\mathrm{P} / \mathrm{O}$ ratio 
Citation: Kavita Kumari K, Setty OH (2012) The Protective Effect of Berberis aristata against Mitochondrial Dysfunction Induced due to Coadministration of Mitomycin C and Cisplatin. J Cancer Sci Ther 4: 199-206. doi:10.4172/1948-5956.1000142

is the number of ATPs produced per pair of electrons traveling through the electron transport system), by $70 \%, 79 \%, 86 \%$ and by $77 \%, 77 \%$, $70 \%$ respectively, with glutamate plus malate (Figure 1 ) and succinate (Figure 2) as substrates. Administration of the B. aristata alone did not show any significant change on the parameters studied above.

\section{Studies on enzymes of electron transport chain}

NADH Dehydrogenase is the first enzyme (Complex I) of the mitochondrial electron transport chain. NADH dehydrogenase is the largest and most complicated enzyme of the electron transport chain [50]. NADH dehydrogenase activity was stimulated by $60 \%$ and $42 \%$ respectively in liver and kidney mitochondria of group-2 (mitomycin $\mathrm{C}$ and cisplatin) when compared to controls (Figure 3 and Figure 4). Prior administration of $B$. aristata could prevent elevation in the activity of NADH dehydrogenase in group -4 (B. aristata + mitomycin $\mathrm{C}$ and cisplatin). It could bring back the activities by $58 \%$ and $83 \%$ in the liver and kidney mitochondria (Figure 3).

Succinate dehydrogenase is a membrane bound component of the respiratory chain of aerobic organisms. In this study succinate dehydrogenase activity was inhibited by $42 \%$ and $30 \%$ respectively in the liver and kidney mitochondria in group-2 (mitomycin C + cisplatin) when compared to control (Figure 3 and 4). Prior administration of $B$. aristata to group 4 rats (Berberis aristata + mitomycin $C+$ cisplatin) relieved the inhibition, by $85 \%$ and $76 \%$ respectively in liver and kidney mitochondria.

The other enzymes of mitochondrial electron transport system that were inhibited were NADH: cytochrome $c$ reductase, Succinate: cytochrome $c$ reductase and cytochrome $c$ oxidase in group-2 (mitomycin $\mathrm{C}+$ cisplatin) rats. These enzymes were inhibited by $37 \%$, $29 \%$ and $34 \%$ respectively in liver (Figure 5) and 37\%, 29\% and 34\% respectively in kidney mitochondria (Figure 6). Prior administration of $B$. aristata could relieve the inhibition on NADH: cytochrome $c$ reductase, succinate : cytochrome $c$ reductase and cytochrome $c$ oxidase, by $86 \%, 100 \%$ and $79 \%$ respectively in liver and by $70 \%, 77 \%$ and $91 \%$ respectively in kidney mitochondria, in group-4 rats (Figure 5 and Figure 6).

\section{Effect on lipid peroxide levels}

Co-administration of mitomycin $\mathrm{C}$ and cisplatin to rats resulted in

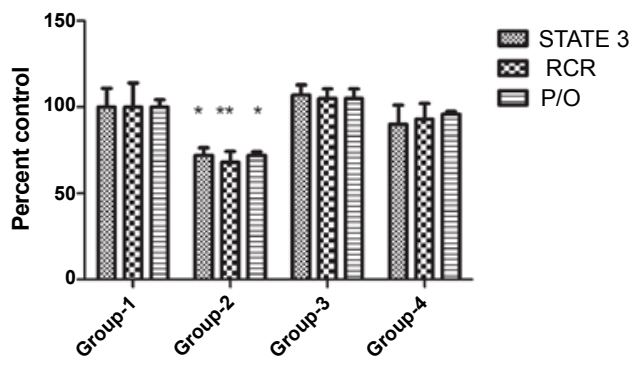

Figure 1: Effect of co-administration of mitomycin $C$ and cisplatin with or without the administration of $B$.aristata on NADH oxidase. Rate of respiration was measured using glutamate + malate as substrate by the addition of $400 \mathrm{n}$ mols of ADP. It was expressed as $n$ moles of oxygen consumed per minute per milligram protein. RCR is the ratio of ADP stimulated state- 3 to ADP exhausted state 4 respiration and $\mathrm{P} / \mathrm{O}=\mathrm{ADP} / \mathrm{O}$ ratio. The control values for state-3 ADP respiration, $\mathrm{RCR}$ and $\mathrm{P} / \mathrm{O}$ ratio were $72 \pm 7.9,4.32 \pm 0.60$ and $2.90 \pm 0.13$ respectively. All the values are expressed relative to controls, which were taken as $100 .{ }^{*} P<0.05$, ${ }^{* *} P<0.01$. Values are Mean \pm SD for at least 13 animals.

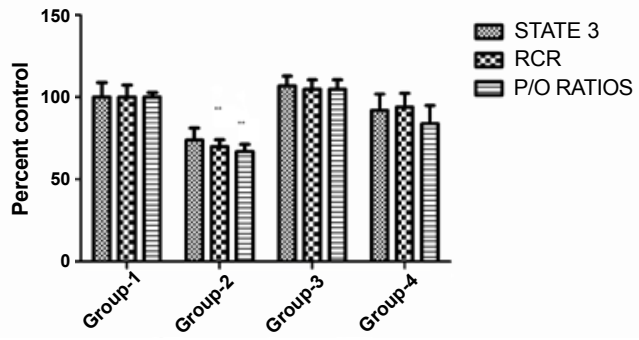

Figure 2: Effect of co-administration of mitomycin $C$ and cisplatin with or without the administration of $B$.aristata on succinate oxidase. The animals were divided into four groups of six animals each. Group-1, received saline, group-2, received a single dose of mitomycin C (2 mg/kg body weight, i.p.) and cisplatin (12 mg/ $\mathrm{kg}$ body weight, i.p). Rats were sacrificed $48 \mathrm{~h}$ after the administration of drugs. Group-3, received alcoholic extract of B.aristata (10 mg/100 g body weight, oral) for three days. Group-4 recieved alcoholic extract of B.aristata $(10 \mathrm{mg} / 100 \mathrm{~g}$ body weight, oral) for three days, followed by single dose of mitomycin C (2 mg/ $\mathrm{kg}$ body weight, i.p) and cisplatin (12 $\mathrm{mg} / \mathrm{kg}$ body weight, i.p). Rats were sacrificed $48 \mathrm{~h}$ after the administration of drugs. Rate of respiration was measured using succinate as substrate by the addition of 200 nmols of ADP. It was expressed as $n$ moles of oxygen per minute per milligram protein. $R C R$ is the ratio of ADP stimulated state- 3 to ADP exhausted state 4 respiration and $P / O=A D P / O$ ratio. Control values for the rate of respiration, $R C R$ and $P / O$ ratio using succinate as a substrate were $120 \pm 11,4.1 \pm 0.31$ and $1.85 \pm 0.056$, respectively. All the values are expressed relative to control, which were taken as 100 . ${ }^{*} P<0.05$, ${ }^{* *} P<0.01$. Values are Mean $\pm S D$ for at least 13 animals

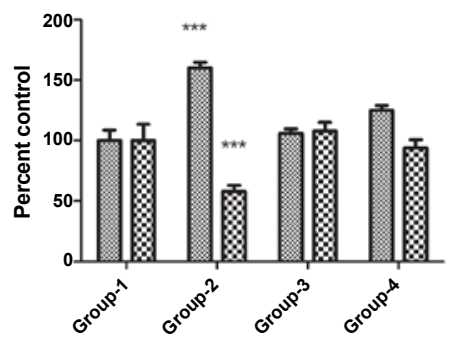

Figure 3: Effect of co-administration of mitomycin $\mathrm{C}$ and cisplatin with or without the administration of $B$.aristata on the rate of on $\mathrm{NADH}$ dehydrogenase and succinate dehydrogenase of liver mitochondria. The animals were divided into four groups of six animals each. Group-1, received saline, Group-2, received a single dose of mitomycin C (2 mg/kg body weight, i.p.) and cisplatin (12 mg/ $\mathrm{kg}$ body weight, i.p). Rats were sacrificed $48 \mathrm{~h}$ after the administration of drugs. Group-3, received alcoholic extract of B.aristata (10 mg/100 g body weight, oral) for three days. Group- 4 received alcoholic extract of B.aristata $(10 \mathrm{mg} / 100 \mathrm{~g}$ body weight, oral) for three days, followed by single dose of mitomycin C (2 mg/ $\mathrm{kg}$ body weight, i.p) and cisplatin (12 mg/kg body weight, i.p). Rats were sacrificed $48 \mathrm{~h}$ after the administration of drugs. NADH dehydrogenase assay: 20 $\mu \mathrm{g}$ of mitochondrial protein was used for each assay NADH $(10 \mathrm{mM})$ was used as substrate. NADH dehydrogenase activity was expressed as $\mathrm{NADH}$ units/min/ $\mathrm{mg}$ protein. (One NADH Unit = One $\mathrm{n}$ mole of potassium ferricyanide reduced / $\mathrm{min} / \mathrm{mg} /$ protein). Succinate dehydrogenase assay: $30 \mu \mathrm{g}$ of mitochondrial protein was used for each assay. Succinate $(9 \mathrm{mM})$ was used as substrate. SDH activity was expressed as SDH units/ min/ mg protein. (One SDH Unit + One $\mathrm{n}$ mole of DCPIP reduced/min/ mg protein). Results are expressed relative to control which was taken as 100 . The control values of NADH dehydrogenase and succinate dehydrogenase were $2750+20$ and $146+20$ respectively in liver mitochondria. ${ }^{\star} P<0.05,{ }^{* *} \mathrm{P}<0.01$, ${ }^{* \star} \mathrm{P}<0.001$. Values are Mean $\pm \mathrm{SD}$ for at least 13 animals.

$75 \%$ and $68 \%$ elevation in the content of free radicals in liver and kidney homogenate in group-2 (mitomycin $\mathrm{C}+$ cisplatin) rats, compared to controls. Prior administration of B. aristata to group-4 (B. aristata + mitomycin $c+$ cisplatin) rats, could relieve inhibition to a significant level (Results not shown). The lipid peroxide levels were measured by the thiobarbutric acid assay. The level of lipid peroxides was expressed as $\mathrm{n}$ moles of MDA formed/ $100 \mathrm{mg}$ protein. The lipid peroxide levels 
estimated in group-2 (mitomycin $\mathrm{C}+$ cisplatin) showed increase by $34 \%$ in liver homogenate, $48 \%$ in liver mitochondria, and $34 \%$ in kidney mitochondria respectively (Figure 7) when compared to control

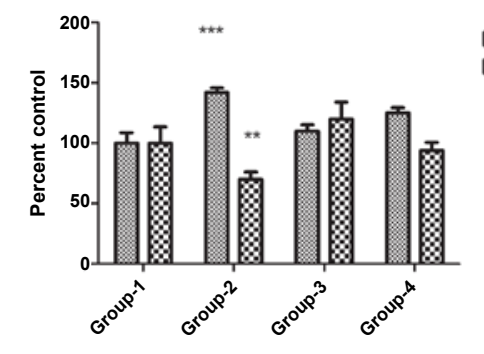

NADH Dehy drogenase

Succinate dehydrogenase

Figure 4: Effect of co-administration of mitomycin $\mathrm{C}$ and cisplatin with or without the administration of B.aristata on the rate of on NADH dehydrogenase and succinate dehydrogenase of kidney mitochondria. The animals were divided into four groups of six animals each. Group-1, received saline, Group-2, received a single dose of mitomycin C (2 mg/kg body weight, i.p) and cisplatin $(12 \mathrm{mg} / \mathrm{kg}$ body weight, i.p). Rats were sacrificed $48 \mathrm{~h}$ after the administration of drugs. Group-3, received alcoholic extract of B.aristata (10 mg/100 g body weight, oral) for three days. Group-4 recieved alcoholic extract of B.aristata $(10 \mathrm{mg} / 100 \mathrm{~g}$ body weight, oral) for three days, followed by single dose of mitomycin $\mathrm{C}(2$ $\mathrm{mg} / \mathrm{kg}$ body weight, i.p) and cisplatin (12 $\mathrm{mg} / \mathrm{kg}$ body weight, i.p). Rats were sacrificed $48 \mathrm{~h}$ after the administration of drugs. Values are mean \pm S.D. from at least six rats in each group. NADH dehydrogenase assay: $20 \mu \mathrm{g}$ of mitochondrial protein was used for each assay $\mathrm{NADH}(10 \mathrm{mM})$ was used as substrate. $\mathrm{NADH}$ dehydrogenase activity was expressed as $\mathrm{NADH}$ units $/ \mathrm{min} / \mathrm{mg}$ Protein (One NADH Unit = One $\mathrm{n}$ mole of potassium ferricyanide reduced $/ \mathrm{min} / \mathrm{mg}$ / protein). Succinate dehydrogenase assay: $30 \mu \mathrm{g}$ of mitochondrial protein was used for each assay. Succinate $(9 \mathrm{mM})$ was used as substrate. SDH activity was expressed as SDH units/ min/ mg protein (One SDH Unit + One $\mathrm{n}$ mole of DCPIP reduced $/ \mathrm{min} / \mathrm{mg}$ protein). Results are expressed as relative to control which was taken as 100 . The control values of $\mathrm{NADH}$ dehydrogenase and succinate dehydrogenase are $2030 \pm 214$ and $107 \pm 14$ respectively in liver mitochondria. Values are Mean \pm SD for at least 13 animals. ${ }^{*} P<0.05$, ${ }^{* *} P<0.01$ and ${ }^{* *} P<0.001$.

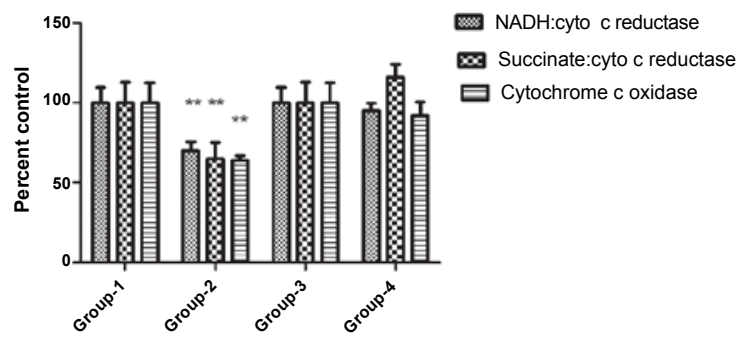

Figure 5: Effect of co-administration of mitomycin $C$ and cisplatin with or without the administration of B.aristata on respiratory chain enzymes. of liver mitochondria. The animals were divided into four groups of six animals each. Group-1, received saline, group 2, received a single dose of mitomycin C (2 mg/ $\mathrm{kg}$ body weight, i.p) and cisplatin (12 $\mathrm{mg} / \mathrm{kg}$ body weight, i.p). Rats were sacrificed $48 \mathrm{~h}$ after the administration of drugs. Group-3, received alcoholic extract of B.aristata (10 mg/100 g body weight, oral) for three days. Group-4 received alcoholic extract of B.aristata (10 mg/100 g body weight, oral) for three days, followed by single dose of mitomycin C ( $2 \mathrm{mg} / \mathrm{kg}$ body weight, i.p) and cisplatin $(12 \mathrm{mg} / \mathrm{kg}$ body weight, i.p). Rats were sacrificed $48 \mathrm{~h}$ after the administration of drugs. NADH: cytochrome $c$ reductase: $20 \mu \mathrm{g}$ of mitochondrial protein was used for each assay. Activity is expressed as $n$ moles of cytochrome $c$ reduced $/ \mathrm{min} / \mathrm{mg}$ protein. Results are expressed relative to control which is taken as 100. The control value was $254+24$. Succinate:cytochrome $c$ reductase: 20 $\mu \mathrm{g}$ of mitochondrial protein was used for each assay. Activity was expressed as $\mathrm{n}$ moles of cytochrome $\mathrm{c}$ reduced $/ \mathrm{min} / \mathrm{mg}$ protein. Results are expressed relative to control which is taken as 100 . The control value was $49+6.4$. Cytochrome $c$ oxidase: $1 \mu \mathrm{g}$ of mitochondrial protein was used for each assay. Reduced cytochrome $c$ was used for each assay. Activity was expressed as $n$ moles of cytochrome $c$ reduced / $\mathrm{min} / \mathrm{mg}$ protein. Results are expressed relative to control which was taken as 100 . The control value is $1138+134$. Values are Mean \pm SD for at least 13 animals. ${ }^{*} p<0.05$, ${ }^{* *} p<0.01$ and ${ }^{* * *} p<0.001$.

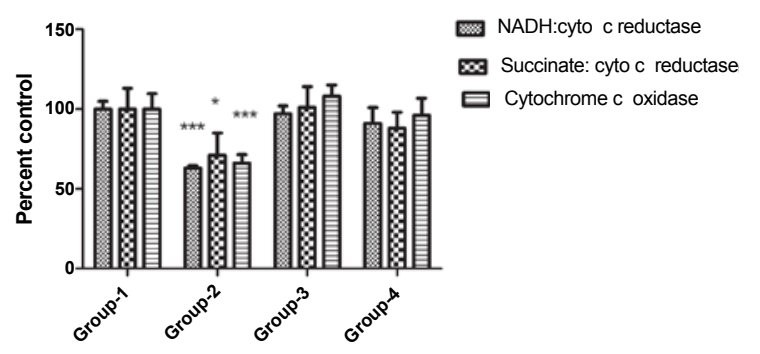

Figure 6: Effect of co-administration of mitomycin C and cisplatin with or without the administration of B.aristata on respiratory chain enzymes.of kidney mitochondria. The animals were divided into four groups of six animals each. Group-1, received saline, group- 2, received a single dose of mitomycin C (2 $\mathrm{mg} / \mathrm{kg}$ body weight, i.p.) and cisplatin (12 $\mathrm{mg} / \mathrm{kg}$ body weight, i.p). Rats were sacrificed $48 \mathrm{~h}$ after the administration of drugs. Group 3, received alcoholic extract of B.aristata (10 mg/100 g body weight, oral) for three days. Group4 received alcoholic extract of B.aristata $(10 \mathrm{mg} / 100 \mathrm{~g}$ body weight, oral) for three days, followed by single dose of mitomycin C (2 mg/kg body weight, i.p ) and cisplatin (12 mg/kg body weight, i.p). Rats were sacrificed $48 \mathrm{~h}$ after the administration of drugs. NADH: cytochrome c reductase: $20 \mu \mathrm{g}$ of mitochondrial protein was used for each assay. Activity is expressed as $n$ moles of cytochrome $c$ reduced $/ \mathrm{min} / \mathrm{mg}$ protein. Results are expressed relative to control which was taken as 100 . The control value was $262+13$. Succinate:cytochrome $c$ reductase: $20 \mu \mathrm{g}$ of mitochondrial protein was used for each assay. Activity is expressed as $\mathrm{n}$ moles of cytochrome $c$ reduced $/ \mathrm{min} / \mathrm{mg}$ protein. Results are expressed relative to control which was taken as 100 . The control value is $33+4.0$. Cytochrome $c$ oxidase: $1 \mu \mathrm{g}$ of mitochondrial protein was used for each assay. Reduced cytochrome $c$ was used for each assay. Activity was expressed as $\mathrm{n}$ moles of cytochrome $c$ reduced $/ \mathrm{min} / \mathrm{mg}$ protein. Results were expressed relative to control which was taken as 100 . The control value is $884+86$. Values are Mean \pm SD for at least 13 animals. ${ }^{*} p<0.05,{ }^{* *} p<0.01$, and ${ }^{{ }^{* * *}} p<0.001$.

group. Prior administration of B. aristata to group-4 rats (B. aristata + mitomycin $\mathrm{C}$ and cisplatin) could protect mitochondria from against lipid peroxide damage by controlling the generation of lipid peroxides completely in liver homogenate, by $70 \%$ in liver mitochondria and $34 \%$ in kidney mitochondria respectively.

\section{Estimation of phospholipid content}

Thin layer chromatography was used for the separation of phospholipids. Mitochondrial lipid was extracted by the procedure of Bligh and Dyer [44]. About 6-8 $\mathrm{mg}$ of mitochondria was used. The phospholipids were separated using Chloroform: methanol: water (65:25:4). Inorganic phosphorus was estimated according to the method of Fiske and Subbarow [45]. It was expressed as phospholipid phosphorus/gm tissue. Administration of mitomycin C plus cisplatin in rats (group-2) resulted in a significant decrease in the phospholipid composition of liver mitochondria, when compared to controls. There was a $29 \%$ decrease in phosphotidyl choline content and $48 \%$ decrease in cardiolipin content where as there was no effect on phosphatidylethanolamine content in group- 2 rats. The total phospholipid content was also decreased by $45 \%$, when compared to controls (Figure 8). Administration of alcoholic extract of $B$. aristata resulted in $79 \%$ and $91 \%$ recovery over the decreased levels of phosphatidylcholine and cardiolipin content whereas there was almost complete recovery, on the decreased levels of total phospholipids. Administration of $B$. aristata alone did not show any significant effects compared to control on any of the parameters studied (Figure 8).

\section{Discussion}

Berberis aristata is spinous shrub native to northern Himalaya region. The plant is distributed from Himalayas to Srilanka, Bhutan and hilly areas of Nepal in Himalaya region. It is found in Himachal 
Pradesh. It is also found in Nilgiris in South India [31]. Studies have revealed its efficacy in giving antimicrobial, hepatoprotective, immunomodulatory, and anti-depressant activities [46]. The decoction of $B$. aristata leaves, commonly known as 'Rashat', is an alternative and deobstruent, and is commonly used to treat skin diseases, menorrhagia, diarrhea, cholera, jaundice, eye and ear infections, as well as urinary tract infections. B. aristata extracts have also been reported to cure hepatotoxicity [46]. In the present investigation alcoholic extract of $B$. aristata was administered to rats for three days at $10 \mathrm{mg} / \mathrm{kg}$ body weight followed by treatment with single dose of mitomycin $\mathrm{c}$ and cisplatin. In order to test whether $B$. aristata is safe by itself, alcoholic extract of $B$. aristata alone was administered to group- 3 rats. The dose and the duration of the treatment of $B$. aristata was standardized. Group-1 rats received saline and were treated as controls (group-1). We believe that after the soon after the administration, these drugs (mitomycin $\mathrm{C}+$ cisplatin) accumulate in liver and kidney [6]. Their accumulation may decrease the antioxidant capacity of tissue, thus leading to generation and accumulation of free radicals. These free radicals, would lead to mitochondrial dysfunction as they could induce metal catalyzed oxidation within the active centers of respiratory chain complexes initiating a chain reaction involving the protein peroxides within the enzyme complexes, finally leading to inactivation of proteins [47-51]. Inactivation of proteins, would result in loss of coordination between the activity of the oxidative chain (complex I to IV) and the ATPase (complex V), ultimately leading to imbalance in ATP which is otherwise tightly regulated in terms of no of ATP generated [52]. Thus, inactivation of proteins may result in uncoupling of oxidative phosphorylation leading to deficiency in the generation of ATP generation or decreased energy levels. Our studies have indicated elevated levels of lipid peroxides in liver homogenate, liver mitochondria and kidney mitochondria of rats treated with mitomycin $\mathrm{C}$ and cisplatin. Lipid peroxides can cause various effects in the cell. The most important one being affecting membrane fluidity, leading to increased permeability to protons, finally leading to uncoupling of oxidative phosphorylation [53] due to covalent modification of membrane proteins [54]. Lipid peroxidation products,

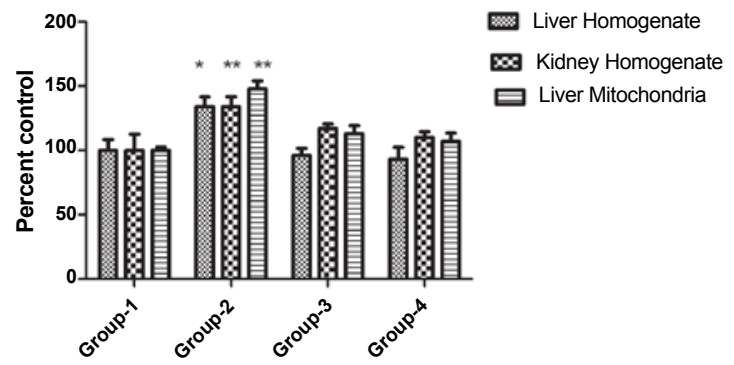

Figure 7: Effect of co-administration of mitomycin $\mathrm{C}$ and cisplatin with or without the administration of $B$. aristata on lipid peroxide level. The animals were divided into four groups of six animals each. Group-1, received saline, Group-2, received a single dose of mitomycin C (2 mg/kg body weight, i.p.) and cisplatin (12 mg/ $\mathrm{kg}$ body weight, i.p). Rats were sacrificed $48 \mathrm{~h}$ after the administration of drugs. Group-3, received alcoholic extract of B.aristata (10 mg/100g body weight, oral) for three days. Group-4 recieved alcoholic extract of B. aristata $(10 \mathrm{mg} / 100 \mathrm{~g}$ body weight, oral) for three days, followed by single dose of mitomycin $C(2 \mathrm{mg} / \mathrm{kg}$ body weight, i.p ) and cisplatin (12 mg/kg body weight, i.p). Rats were sacrificed $48 \mathrm{~h}$ after the administration of drugs. $2 \mathrm{mg}$ of protein was used for each assay. Tetramethoxypropane was used as an external standard. Lipid peroxide level is expressed as $\mathrm{n}$ moles MDA formed $/ 100 \mathrm{mg}$ protein. Results were expressed relative to control which was taken as 100 . The control values are 139 $11.7,149 \pm 19$ and $76 \pm 2.1$ for liver homogenate, kidney homogenate and liver mitochondria. Values were Mean \pm SD for at least 13 animals. ${ }^{*} p<0.05,{ }^{* *} p<0.01$ and ${ }^{* * *} p<0.001$.

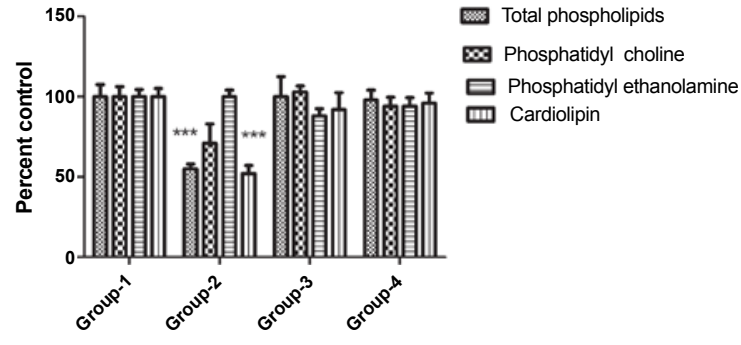

Figure 8: Effect of co-administration of mitomycin $C$ and cisplatin with or without the administration of B.aristata on phospholipid composition of liver mitochondria. The animals were divided into four groups of six animals each. Group-1, received saline, group-2, received a single dose of mitomycin C (2 mg/kg body weight, i.p.) and cisplatin (12 $\mathrm{mg} / \mathrm{kg}$ body weight, i.p). Rats were sacrificed $48 \mathrm{~h}$ after the administration of drugs. Group-3, received alcoholic extract of $B$.aristata (10 mg/100 g body weight, oral) for three days. Group-4 received alcoholic extract of B.aristata (10 mg/100 g body weight, oral) for three days, followed by single dose of mitomycin C (2 mg/kg body weight, i.p) and cisplatin (12 mg/kg body weight, i.p). Rats were sacrificed $48 \mathrm{~h}$ after the administration of drugs. All the values are expressed relative to the control, which is taken as 100 . The control values of are $24 \pm 1.8,32 \pm 2.0,26 \pm 1.2$ and $36 \pm 1.0$ for total phospholipids, phosphatidylcholine, phosphatidylethanolamine and cardiolipin respectively. Values are Mean \pm SD for at least 13 animals. ${ }^{*} p<0.05,{ }^{* *} p<0.01$ and ${ }^{* * *} p<0.001$.

lipid hydroperoxides, generate very reactive unsaturated aldehydes like 4-hydroxy 2-nonenal (4-HNE), malondialdehyde (MDA), and acrolein, which can induce a chain reaction leading to the generation of new radicals which intensifies lipid peroxidation. In mitochondrial membranes, unsaturated fatty acids, being components of phospholipids, are very susceptible to oxidation by the hydroxyl radical. Our present investigation on mitomycin $\mathrm{C}$ and cisplatin also proves this point, the decrease in total content of phospholipids along with decreased content of other phospholipids mainly phosphotidylinositol, phosphotidyl ethanolamine and cardiolipin indicates lipid peroxides mediated damage to phospholipids of mitochondrial membrane. In earlier studies, alterations in cardiolipin also have been linked with mitochondrial membrane proteins altered activities of $\mathrm{NADH}$ dehydrogenase [55] and cytochrome $c$. Our observations, with respect to increased activities of NADH dehydrogenase and inhibited activities of cytochrome $c$ oxidase could be related to alterations in cardiolipin content, due to lipid peroxides generated by free radicals. Furthermore, previous investigations by Sanchez-Alcazar et al. [56] reported that, teniposide and other chemotherapeutic agents increased the levels of proteins of the mitochondrial respiratory chain, such as cytochrome $c$, and subunits I and IV of COX, suggesting that the increase in mitochondrial protein expression may play a role in the early cellular defense against anticancer drugs. Cardiolipin appears to be major signaling factor in this whole cascade of events. It has been reported that under normal conditions, the cardiolipin-bound cytochrome $c$ assumes the role of a membrane-bound peroxidase, that can effectively catalyze oxidative stress and cause oxidation of Cardiolipin. However, under oxidative stress, membrane-bound cytochrome $c$ acts as a mitochondrial death receptor, transducing proapoptotic signals into executing oxidative cascades with a consequent overload of oxidized cardiolipin species, detachment of cytochrome $c$ from the membrane and formation of mitochondrial permeability transition pore (mPTP) and collapse of mitochondrial membrane potential, mitochondrial swelling, cytochrome $c$ release and the subsequent engagement of the Apaf-1-pro-caspase 9 apoptosome complex, which activates downstream effector caspases leading finally to apoptosis [57]. We believe that the consequence of above mentioned events manifests 
Citation: Kavita Kumari K, Setty OH (2012) The Protective Effect of Berberis aristata against Mitochondrial Dysfunction Induced due to Coadministration of Mitomycin C and Cisplatin. J Cancer Sci Ther 4: 199-206. doi:10.4172/1948-5956.1000142

as adverse effects of chemotherapy; excessive sweating (uncoupling of oxidative phosphorylation is another well-defined mechanism for mitochondrial toxicity. Uncoupling means that the protons, shifted from the mitochondrial matrix to the space between inner and outer membrane, do not pass across the F0F1ATPase (complex V) back to the mitochondrial matrix, but instead go directly across the inner mitochondrial membrane. The result is production of heat, but not of energy in the form of ATP), fatigue and less energy to perform various activities (decreased ATPase activity along with decreased membrane potential finally leading to deficiency of ATP which means decreased energy levels), Hepatic or renal dysfunction as ATPdepletion may induce ultra structural changes in liver and kidney cells, the primary cell injury and programmed cell death, this in turn may accelerate reactive oxygen metabolites formation by the damaged cells, which may contribute to an amplification loop leading to reactive oxygen metabolites -mediated cell death of the same cell or even the neighboring cells [58].

Our studies prove protective effects of B. aristata on mitochondrial dysfunction induced by mitomycin $\mathrm{C}$ and cisplatin. The mechanism of protection offered by the plant extract was not included in the present investigation but based on the results obtained could be by the following mechanism; a) By scavenging free radicals, thus preventing uncoupling of oxidative phosphorylation, protecting enzymes of electron transport chain from deactivation and hence restoring ATPase activity and membrane potential, protecting against lipid peroxidation of phospholipids and preventing detachment of cardiolipin from cytochrome $c$, as this could result in transduction of proapoptotic signals leading to changes in permeability of mitochondrial membrane ultimately leading to apoptosis. Furthermore, we believe that it may offer protection against induction of apoptosis by either the pathways (intrinsic and extrinsic) as there is evidence that the two pathways are linked and that molecules in one pathway can influence the other [59]. Although there are no direct evidences showing $B$. aristata extracts causing the inhibition of apoptotic signal generated by chemotherapeutic agents, but the work done by Zhou et al. [60] elegantly demonstrates, that berberine shows its protective effect by decreasing ROS and there by inhibiting mitochondrial apoptotic pathway. However, the protective effect of $B$. aristata against cisplatin induced nephrotoxicity is already reported [61] which is an evidence that $B$. aristata extracts could be exerting effect by the inhibition of apoptotic signal generated by chemotherapeutic agents. b) By modulation of the glycolytic pathway thereby, increasing NADPH production (with a consequent decrease in intracellular ROS levels) and lowering the sensitivity of cells to p53-dependent apoptosis induced by oxidative stress [62]. c) By the inhibition of MDME enzymes [63]. The active principle involved in the antioxidant effect is not known yet and can be attributed to Berberine and palamatine, which are major alkaloids found in Berberis aristata [64].

In conclusion, our work elucidates the mechanism of oxidative stress observed due to administration of mitomycin $C$ and cisplatin and proves beneficial effects of $B$. aristata in reducing drug related toxicity.

\section{Acknowledgment}

The corresponding author would like to thank Council for Scientific and Industrial Research (CSIR) for giving financial assistance during the work. This article is the part of thesis work.

\section{Conflict of Interest}

Author has no conflict of interests.

\section{References}

1. Ali BH, Moundhri MS (2006) Agents ameliorating or augmenting the nephrotoxicity of cisplatin and other platinum compounds: a review of some recent research. Food Chem Toxicol 44: 1173-1183.

2. Somani SM, Husain K, Whitworth C, Trammell GL, Malafa M, et al. (2000) Dosedependent protection by lipoic acid against cisplatin-induced nephrotoxicity in rats: antioxidant defense system. Pharmacol Toxicol 86: 234-241.

3. Winston JA, Safirstein R (1985) Reduced renal blood flow in early cisplatininduced acute renal failure in the rat. Am J Physiol 249: F490-F496.

4. Chirino YI, Hernández-Pando R, Pedraza-Chaverí J (2004) Peroxynitrite decomposition catalyst ameliorates renal damage and protein nitration in cisplatin-induced nephrotoxicity in rats. BMC Pharmacol 4: 20-29.

5. Hanigan MH, Devarajan P (2003) Cisplatin nephrotoxicity: molecular mechanisms. Cancer Ther 1: 47-61.

6. Litterst CL, Torres IJ, Arnold S, McGunagle D, Furner R, et al. (1982) Adsorption of antineoplastic drugs following large-volume ip administration to rats. Cancer Treat Rep 66: 147-155

7. Fisher DE (1994) Apoptosis in cancer therapy: crossing the threshold. Cell 78 539-542.

8. Sorenson CM, Eastman A (1988) Influence of cis-diamminedichloroplatinum (II) on DNA synthesis and cell cycle progression in excision repair proficient and deficient Chinese hamster ovary cells. Cancer Res 48: 6703-6707.

9. Sorenson CM, Eastman A (1988) Mechanism of cis-diamminedichloroplatinum (II)-induced cytotoxicity: role of G2 arrest and DNA double-strand breaks. Cancer Res 48: 4484-4488.

10. Fuertesa MA, Castilla J, Alonso C, Perez JM (2003) Cisplatin biochemica mechanism of action: from cytotoxicity to induction of cell death through interconnections between apoptotic and necrotic pathways. Curr Med Chem 10: $257-266$

11. Gonzalez VM, Fuertes MA, Alonso C, Perez JM (2001) Is cisplatin-induced cell death always produced by apoptosis? Mol Pharmacol 59: 657-663.

12. Mandic A, Hansson J, Linder S, Shoshan MC (2003) Cisplatin induces endoplasmic reticulum stress and nucleus-independent apoptotic signaling. $J$ Biol Chem 278: 9100-9106

13. Liu H, Baliga R (2005) Endoplasmic reticulum stress-associated caspase 12 mediates cisplatin-induced LLC-PK1 cell apoptosis. J Am Soc Nephrol 16: 1985-1992.

14. Yu F, Megyesi J, Price PM (2008) Cytoplasmic initiation of cisplatin cytotoxicity. Am J Physiol Renal Physiol 295: F44-F52.

15. Sheikh-Hamad D, Timmins K, Jalali Z (1997) Cisplatin-induced renal toxicity: possible reversal by $\mathrm{N}$-acetylcysteine treatment. J Am Soc Nephrol 8: 1640 1644.

16. Verweij J, Pinedo HM (1990) Mitomycin C: mechanism of action, usefulness and limitations. Anticancer Drugs 1: 5-13.

17. Bradner WT (2001) Mitomycin C: a clinical update. Cancer Treat Rev 27: 35-50.

18. Saikawa Y, Kubota T, Kuo TH, Furukawa T, Kase S, et al. (1994) Synergistic antitumor activity of combination chemotherapy with mitomycin $\mathrm{C}$ and cisplatin against human gastric cancer xenografts in nude mice. J Surg Oncol 56: 242245

19. Tonato M, Crinó L, Mosconi AM (1997) Rationale of a phase Ill study comparing standard cisplatin regimen (mitomycin/ifosfamide/cisplatin) with cisplatin and gemcitabine in non-small cell lung cancer. Semin Oncol 24: S8-31-S8-35.

20. Durand RE (1989) Synergism of cisplatin and mitomycin C in sensitive and resistant cell subpopulations of a tumor model. Int J Cancer 44: 911-917.

21. Ellis PA, Smith, IE, Hardy JR, Nicolson MC, Talbot DC, et al. (1995) Symptom relief with MVP (mitomycin C, vinblastine and cisplatin) chemotherapy in advanced non-small-cell lung cancer. Br J Cancer 71: 366-370.

22. Urruticoechea A, Archer CD, Assersohn LA, Gregory RK, Verrill M, et al. (2005) Mitomycin C, vinblastine and cisplatin (MVP): an active and well-tolerated salvage regimen for advanced breast cancer. Br J Cancer 92: 475-479.

23. Huang TG, Ip SM, Yeung WS, Ngan HY (2001) Mitomycin C and Cisplatin Enhanced the Antitumor Activity of p53-expressing Adenovirus in cervical cancer cells. Cancer Invest 19: 360-368. 
Citation: Kavita Kumari K, Setty OH (2012) The Protective Effect of Berberis aristata against Mitochondrial Dysfunction Induced due to Coadministration of Mitomycin C and Cisplatin. J Cancer Sci Ther 4: 199-206. doi:10.4172/1948-5956.1000142

24. Mitchell P Moyle J (1969) Translocation of some anions cations and acids in rat liver mitochondria. Eur J Biochem 9: 149-155

25. Suski J, Lebiedzinska M, Machado NG, Oliveira PJ, Pinton P, et al. (2011) Mitochondrial tolerance to drugs and toxic agents in ageing and disease. Curr Drug Targets 12: 827-849.

26. Sebastian T, Setty $\mathrm{OH}(1999)$ Protective effect of $P$. fraternus against ethanol induced mitochondrial dysfunction. Alcohol 17: 29-34

27. Padma P, Setty OH (1997) Protective effect of Phyllanthus fraternus against thioacetamide-induced mitochondrial dysfunction. J Clin Biochem Nutr 22: 113123.

28. Padma P, Setty OH (1999) Protective effect of Phyllanthus fraternus agains carbon tetrachloride-induced mitochondrial dysfunction. Life Sci 64: 2411-2417.

29. Kumari KK, Setty OH (2012) Protective effect of Phyllanthus fraternus agains mitochondrial dysfunction induced by co-administration of cisplatin and cyclophosphamide. J Bioenerg Biomembr 44: 179-188.

30. Pinmai K, Chunlaratthanabhorn S, Ngamkitidechakul C, Soonthornchareon N Hahnvajanawong C (2008) Synergistic growth inhibitory effects of Phyllanthus emblica and Terminalia bellerica extracts with conventional cytotoxic agents: doxorubicin and cisplatin against human hepatocellular carcinoma and lung cancer cells. World J Gastroenterol 14: 1491-1497.

31. Komal S, Ranjan B, Neelam C, Birendra S, Kumar SN (2011) Berberis Aristata: A Review. Int J Res Ayvd Pharm 2: 383-388.

32. Sohni YR, Bhatt RM (1996) Activity of a crude extract formulation in experimenta hepatic amoebiasis and in immunomodulation studies. J Ethnopharmacol 54 $119-124$

33. Gilani AH, Janbaz KH (1995) Preventive and curative effects of Berberis aristata fruit extract on paracetamol and $\mathrm{CCl} 4$-induced hepatotoxicity. Phytother Res 9 : 489-494

34. Lawrence CB, Davis NT (1986) A novel, simple and rapid method for the isolation of mitochondria which exhibit respiratory control, from small intestinal mucosa. Biochim Biophys Acta 848: 35-40

35. Gornall AG, Bardawill CJ, David MM (1949) Determination of serum proteins by means of the biuretic reaction. J Biol Chem 177: 751-766.

36. Estabrook RW (1967) Mitochondrial respiratory control and the polarographic measurements of ADP:O ratios. In: Estabrook RW, Pullman ME (Eds), Methods in enzymology, (10th Edn), Academic, New York 41-47.

37. King TE, Robert HL (1967) [52] Preparation and properties of soluble NADH dehydrogenase from cardiac muscle. Methods in Enzymology 10: 275-294.

38. King TE (1967) Preparation of succinate dehydrogenase and reconstitution of succinate oxidase. In: Estabrook RW, Pullman ME (Eds) Methods in enzymology Academic press Inc, New York 10: 322-331.

39. Tisdale TD (1967) In: Estabrook RW, Pullman ME (Eds), Methods in enzymology. Academic, New York 10: 213-215.

40. Hatefi Y, Reiske JS (1967) In: Estabrook RE, Pullman ME (Eds), Methods in enzymology, Academic, New York 10: 225-231.

41. Cooperstein SJ, Lazarow A (1951) A microspectrophotometric method for the determination of cytochrome oxidase. J Biol Chem 189: 665-670.

42. Yonetani T (1967) Methods in Enzymology. In: Estrabrook RW, Pullman ME (Eds), Cytochrome oxidase: beef heart. Academic Press, New York 10: 332 335.

43. Ohkawa H, Ohishi N, Yagi K (1979) Assay for lipid peroxides in animal tissue by thiobarbituric acid reaction. Annal. Biochem 95: 351-358.

44. Bligh EG, Dyer WJ (1959) A rapid method of total lipid extraction and purification. Can J Biochem Physiol 37: 911-917.

45. Fiske $\mathrm{CH}$, Subbarow $\mathrm{Y}(1925)$ The colorimetric determination of phosphorus. J Biol Chem 66: 375-400

46. Mazumder PM, Saumya D , Sanjita D, Manas Kumar D (2011) PHYTOPHARMACOLOGY of Berberis aristata DC: A REVIEW. J Drug Deliv 1: 46-50.

47. Ackrell BAC, Johnson MK, Gunsalus RP, Cecchini G (1992) Structure and function of succinate dehydrogenase and fumarate reductase. In: Muller F (Eds), Chemistry and Biochemistry of Flavoproteins. Boca Raton, FL: CRC Press 3: 229-297.
48. Rustin P, Munnich M, Rotig A (2002) Succinate dehydrogenase and human diseases: new insights into a well-known enzyme. Eur J Hum Genet 10: 289 291.

49. Santiago E, López-Moratalla N, Segovia JL, Eugui J (1977) NADH-cytochrome C reductase, succinate cytochrome c reductase and phospholipids. Rev Esp Fisiol 33: 197-204

50. Dos Santos NA, Martins NM, Curti C, Bianchi MLP, dos Santos AC (2007) Dimethylthiourea protects against mitochondrial oxidative damage induced by cisplatin in liver of rats. Chem Biol Int 170: 177-186.

51. Szewczyk A, Wojtczak L (2002) Mitochondria as a pharmacological target Pharmacol Rev 54: 101-127.

52. Gordon JA, Gattone VH 2nd (1986) Mitochondrial alterations in cisplatininduced acute renal failure. Am J Physiol 250: F991-F998.

53. Huang $\mathrm{H}$, Manton KG (2004) The role of oxidative damage in mitochondria during aging: a review. Front Biosci 9: 1100-1117.

54. Sayre LM, Lin D, Yuan Q, Zhu X, Tang X (2006) Protein adducts generated from products of lipid oxidation: focus on HNE and one. Drug Metab Rev 38: 651-675.

55. Paradies G, Petrosillo G, Pistolese M, Ruggiero FM (2002) Reactive oxygen species affect mitochondrial electron transport complex I activity through oxidative cardiolipin damage. Gene 286: 135-141.

56. Sanchez-Alcazar JA, Khodjakov A, Schneider E (2001) Anticancer drugs induce increased mitochondrial cytochrome $\mathrm{c}$ expression that precedes cell death. Cancer Res 61: 1038-1044.

57. Marchi S, Giorgi C, Suski JM, Agnoletto C, Bononi A, et al. (2012) MitochondriaRos Crosstalk in the Control of Cell Death and Aging. J Signal Transduct 2012 $1-17$.

58. Fuertesa MA Castillab J, Alonso C, Perez JM (2003) Cisplatin biochemica mechanism of action: from cytotoxicity to induction of cell death through interconnections between apoptotic and necrotic pathways. Curr Med Chem 10: $257-266$

59. Igney $\mathrm{FH}$, Krammer PH (2002) Death and anti-death: tumour resistance to apoptosis. Nat Rev Cancer 2: 277-288.

60. Zhou XQ, Zeng XN, Kong H, Sun XL (2008) Neuroprotective effects of berberine on stroke models in vitro and in vivo. Neurosci Lett 447: 31-36.

61. Sreedevi A, Bharathi K, Prasad, KVSRG (2010) Effect of decoction of roo bark of berberis aristata against cisplatin induced nephrotoxicity in rats. Int $J$ Pharmacy Pharm Sci 2: 51-56.

62. Bensaad K, Tsuruta A, Selak MA, Vidal MN, Nakano K, et al. (2006) TIGAR, a p53-inducible regulator of glycolysis and apoptosis. Cell 126: 107-120.

63. Sohni YR, Bhatt RM (1996) Activity of a crude extract formulation in experimenta hepatic amoebiasis and in immunomodulation studies. J Ethnopharmacol 54 119-124.

64. Chatteriiee RP (1951) Isolation of new phytoconstituents from the plants of Berberidaceae family. J Indian Chem Soc 28: 225. 